Case Report

\title{
A Pregnant Woman Who Underwent Laparoscopic Adrenalectomy due to Cushing's Syndrome
}

\author{
Halit Diri, ${ }^{1}$ Fahri Bayram, ${ }^{1}$ Yasin Simsek, ${ }^{1}$ Yusuf Ozkan, ${ }^{2}$ Alper Akcan, ${ }^{3}$ Ibrahim Karahan, ${ }^{4}$ \\ Ibrahim Ileri, ${ }^{5}$ Sulbiye Aribas, ${ }^{1}$ and Mehmet Sait Koc ${ }^{1}$ \\ ${ }^{1}$ Division of Endocrinology, Erciyes University Medical School, 38039 Kayseri, Turkey \\ ${ }^{2}$ Division of Endocrinology, Firat University Medical School, 23000 Elazı̆̆, Turkey \\ ${ }^{3}$ Department of General Surgery, Erciyes University Medical School, 38039 Kayseri, Turkey \\ ${ }^{4}$ Department of Radiology, Erciyes University Medical School, 38039 Kayseri, Turkey \\ ${ }^{5}$ Department of Internal Diseases, Erciyes University Medical School, 38039 Kayseri, Turkey
}

Correspondence should be addressed to Halit Diri; halitdiri@yahoo.com

Received 18 August 2014; Accepted 18 November 2014; Published 3 December

Academic Editor: Wayne V. Moore

Copyright (C) 2014 Halit Diri et al. This is an open access article distributed under the Creative Commons Attribution License, which permits unrestricted use, distribution, and reproduction in any medium, provided the original work is properly cited.

Cushing's syndrome (CS) may lead to severe maternal and fetal morbidities and even mortalities in pregnancy. However, pregnancy complicates the diagnosis and treatment of CS. This study describes a 26-year-old pregnant woman admitted with hypertensioninduced headache. Hormonal analyses performed due to her cushingoid phenotype revealed a diagnosis of adrenocorticotropic hormone- (ACTH-) independent CS. MRI showed a $3.5 \mathrm{~cm}$ adenoma in her right adrenal gland. After preoperative metyrapone therapy, she underwent a successful unilateral laparoscopic adrenalectomy at 14-week gestation. Although she had a temporary postoperative adrenal insufficiency, hormonal analyses showed that she has been in remission since delivery. Findings in this patient, as well as those in previous patients, indicate that pregnancy is not an absolute contraindication for laparoscopic adrenalectomy. Rather, such surgery should be considered a safe and efficient treatment method for pregnant women with cortisol-secreting adrenal adenomas.

\section{Introduction}

Pregnancy is rare in premenopausal women with Cushing's syndrome (CS), because secretion of excess glucocorticoids inhibits the synthesis of gonadotropins, resulting in disorders in ovarian and endometrial functions, as well as amenorrhea or oligomenorrhea [1]. Furthermore, even if CS patients become pregnant, the incidence of serious complications is high. CS may cause maternal hypertension, diabetes mellitus/impaired glucose tolerance, osteopenia/osteoporosis, preeclampsia, pulmonary edema, heart failure, opportunistic infections, and even death [2-5]. In addition, CS may cause stillbirth, prematurity, and intrauterine growth restriction of the fetus [2-5]. Although it is crucial to recognize CS early in pregnancy, the diagnosis of CS may be overlooked due to the overlapping signs of preeclampsia and/or gestational diabetes.
In addition to its manifestations, including hypertension, hyperglycemia, and hypercortisolemia, the underlying etiology of CS must also be effectively treated in pregnant women. This underlying etiology includes adrenal adenomas, present in $15 \%$ of nonpregnant female patients with CS and in approximately $50 \%$ of pregnant women with this disorder $[2,3,6]$. Laparoscopic adrenalectomy is the first line treatment of choice in patients with cortisol-secreting adrenal adenomas, while medical treatment is suggested when surgery is contraindicated $[7,8]$. Additionally, medical treatment should be administered preoperatively to decrease the likelihood of complications that occur due to adrenalectomy in patients with severe CS. Metyrapone is a preferred agent, because it has very rarely reported side effects in pregnancy. It may rarely exacerbate hypertension and thus cause preeclampsia [4, 9-11], and fetal hypoadrenalism may develop after metyrapone [12]. Ketoconazole is shown to 


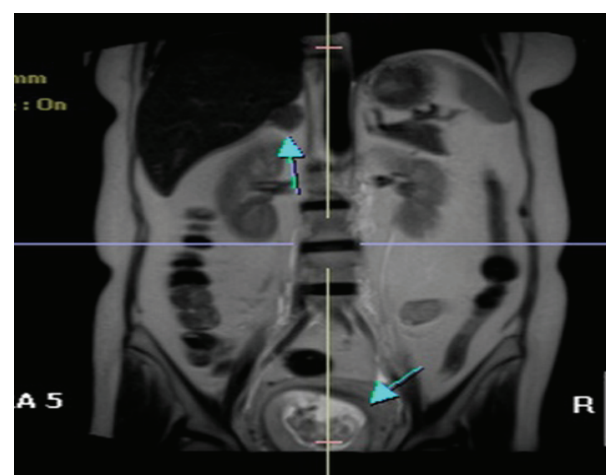

FIGURE 1: MR image of the adrenal adenoma and intrauterine fetus.

cross placenta and can be teratogenic; thus it is in FDA category C [4].

Since CS is rarely encountered in pregnant women, laparoscopic adrenalectomy is rarely performed on pregnant women with adrenocorticotropic hormone- (ACTH-) independent CS. Here we describe a pregnant woman diagnosed with CS who underwent a successful unilateral laparoscopic adrenalectomy.

\section{Case}

A 26-year-old, gravid-2 para-1, 12-week pregnant woman was admitted to another hospital for headache and hypertension. A physical examination showed a body-mass index of $31.8 \mathrm{~kg} / \mathrm{m}^{2}$, central obesity, hypertension $(180 / 100 \mathrm{mmHg})$, a moon face, fascial plethora, and abdominal purple striae $>1 \mathrm{~cm}$ wide. Hence, CS was suspected, and she was referred to Erciyes University Medical School.

Firstly, she was treated with methyldopa to control her hypertension. Complete blood count and biochemistry tests including plasma glucose, liver and renal functions, and electrolytes were normal. Fetal ultrasound imaging was also normal and intrauterine growth restriction was not reported. Subsequent hormonal analyses showed a serum cortisol concentration of $48.2 \mu \mathrm{g} / \mathrm{dL}$ after a $2 \mathrm{mg}$ low dosedexamethasone suppression test (LD-DST), a midnight serum cortisol concentration while awake of $32.0 \mu \mathrm{g} / \mathrm{dL}$, and a urine free cortisol (UFC) concentration of $2358 \mu \mathrm{g} / 24 \mathrm{~h}$ (normal: $55-280 \mu \mathrm{g} / 24 \mathrm{~h}$ ). In addition, baseline serum cortisol and ACTH concentrations were $44.4 \mu \mathrm{g} / \mathrm{dL}$ and $4.08 \mathrm{pg} / \mathrm{mL}$, respectively, and serum cortisol concentration after $8 \mathrm{mg}$ high dose-DST was $48.7 \mu \mathrm{g} / \mathrm{dL}$. The patient was diagnosed with ACTH-independent CS, and the diagnosis was confirmed by magnetic resonance imaging, which showed a $3.5 \times 2.5 \mathrm{~cm}$ adenoma in her right adrenal gland (Figure 1).

The management of her hypertension became easier after metyrapone before the adrenalectomy, probably due to lower cortisol levels. After 6 days of metyrapone, the patient successfully underwent a unilateral laparoscopic adrenalectomy at 14-week gestation. The surgery was performed under general anesthesia; during the operation she was placed in the left lateral decubitus position. Carbon dioxide was used for insufflation of the peritoneal cavity to intra-abdominal pressure of $10 \mathrm{mmHg}$. No complications developed during surgery. Four days after surgery, her serum cortisol concentration, in a blood sample taken at 08:00 a.m., was $2.8 \mu \mathrm{g} / \mathrm{dL}$. The patient, who also had fatigue and anorexia, was administered $20 \mathrm{mg}$ bid hydrocortisone replacement due to adrenal insufficiency. Since the patient did not have any medical problems and her hypertension had improved without drugs after surgery, she was discharged two weeks after the laparoscopic adrenalectomy.

The pathological examination of the removed adenoma was consistent with an adrenocortical adenoma. A followup visit performed 2 months after discharge and 2 days after discontinuation of hydrocortisone showed a serum cortisol concentration of $22.4 \mu \mathrm{g} / \mathrm{dL}$. Replacement therapy was therefore stopped and 1 week after, the cortisol level was $1.75 \mu \mathrm{g} / \mathrm{dL}$ after $1 \mathrm{mg}$ DST. She gave birth to a healthy baby at 41-week gestation by normal delivery. The baby's birth weight was $3.0 \mathrm{~kg}$. Two and eight months after delivery, $1 \mathrm{mg}$ DSTs showed cortisol concentrations of 1.05 and $1.40 \mu \mathrm{g} / \mathrm{dL}$, respectively, indicating that she remained in remission.

\section{Discussion}

The physiological increases in pituitary-adrenal axis activity during pregnancy cause serum ACTH, corticosteroid binding protein, total and free cortisol, and UFC concentrations to increase [4]. Therefore, pregnancy-induced physiological hypercortisolemia complicates the diagnosis of CS [13]. Measurements of midnight serum and salivary cortisol concentrations, $2 \mathrm{mg}$ LD-DST, and UFC concentration are recommended for the diagnosis of CS in pregnant women suspected of having the disease [14-16], with positive results in two or more of these tests diagnostic for CS [17]. However, the threshold values may be higher in pregnant than in nonpregnant women. Because UFC increases throughout gestation, UFC concentrations 3-fold higher than the upper limit of normal for nonpregnant women should be regarded as the threshold during the second and third trimesters of pregnancy $[18,19]$. Similarly, midnight salivary cortisol concentrations during the third trimester of pregnancy are twice as high as in nonpregnant women [20]. The likelihood of false-positive results on $1 \mathrm{mg}$ DST is very high in pregnant women, making it logical to perform $2 \mathrm{mg} \mathrm{LD}$ DST in pregnant women suspected of having CS. Serum ACTH concentrations are not suppressed in about half of pregnant women with cortisol-secreting adrenal adenoma due to placental CRH $[4,16]$. In contrast, the circadian rhythm is preserved in healthy pregnant women $[18,21]$.

The combination of a typical cushingoid phenotype, very high cortisol concentrations, low basal ACTH concentration, and adrenal adenoma images on MRI led to a diagnosis of ACTH-independent CS in our patient. As these diagnostic analyses were performed during an early stage of pregnancy, the patient's serum ACTH concentration may have been suppressed by low levels of placental CRH.

It is not necessary to postpone the treatment of adrenal adenoma induced CS until after delivery because of concerns about complications of treatment methods [22, 23]. Due to 
the possible side effects of long-term medical therapy, such as hypertension and preeclampsia [9-11], surgery performed by an experienced team should be the first choice of treatment $[7,8]$. Administering medical therapy until delivery may increase the likelihood of side effects and fetal problems such as hypoadrenalism [12]. On the other hand, it should be kept in mind that surgical complications may occur with a nonexperienced surgical team.

Surgery should preferentially be performed during the second trimester of pregnancy $[8,23,24]$. Although adrenalectomies performed during the third trimester have been reported to be successful $[5,6,8,25]$, administering medical therapy and delaying surgery until after delivery is more convenient in pregnant women diagnosed with CS during the last weeks of the third trimester [8].

Due to the risks of surgical complications during pregnancy, few pregnant women with adrenal CS have undergone adrenalectomy to date. Case reports, however, have indicated that the laparoscopic approach is safe, with the rates showing that maternal and fetal complications are higher in untreated than in surgically treated patients [26]. The major advantages of laparoscopic surgery are less intraoperative blood loss, less postoperative pain, more rapid wound healing, and earlier postoperative mobilization $[27,28]$. Since the most frequently encountered surgical complication in pregnant women is persistent pneumoperitoneum after surgery, insufflation of the peritoneal cavity should not exceed $12 \mathrm{mmHg}$ pressure [29].

Our findings indicate that pregnancy is not an absolute contraindication for laparoscopic adrenalectomy. In contrast, such surgery should be considered a safe and efficient treatment method for a pregnant woman with adrenal CS. Cortisol-secreting adrenal adenomas in pregnant women should be diagnosed and treated by experienced teams of related departments, with laparoscopic adrenalectomy regarded as the mainstay of treatment.

\section{Conflict of Interests}

The authors declare that there is no conflict of interests regarding the publication of this paper.

\section{References}

[1] M. A. Magiakou, G. Mastorakos, E. Webster, and G. P. Chrousos, "The hypothalamic-pituitary-adrenal axis and the female reproductive system," Annals of the New York Academy of Sciences, vol. 816, pp. 42-56, 1997.

[2] D. C. Aron, A. M. Schnall, and L. R. Sheeler, "Cushing's syndrome and pregnancy," American Journal of Obstetrics \& Gynecology, vol. 162, no. 1, pp. 244-252, 1990.

[3] M. A. Buescher, H. D. McClamrock, and E. Y. Adashi, "Cushing syndrome in pregnancy," Obstetrics and Gynecology, vol. 79, no. 1, pp. 130-137, 1992.

[4] J. R. Lindsay and L. K. Nieman, "The hypothalamic-pituitaryadrenal axis in pregnancy: challenges in disease detection and treatment," Endocrine Reviews, vol. 26, no. 6, pp. 775-799, 2005.

[5] Y. M. Nakashima, Y. Itonaga, H. Inoue, and S. Takahashi, "Pulmonary edema after laparoscopic adrenalectomy in a pregnant patient with Cushing's syndrome," Journal of Anesthesia, vol. 14, no. 3, pp. 157-159, 2000.

[6] J. Pickard, A. L. Jochen, C. N. Sadur, and F. D. Hofeldt, "Cushing's syndrome in pregnancy," Obstetrical \& Gynecological Survey, vol. 45, no. 2, pp. 87-93, 1990.

[7] A. Upadhyay, S. Stanten, G. Kazantsev, R. Horoupian, and A. Stanten, "Laparoscopic management of a nonobstetric emergency in the third trimester of pregnancy," Surgical Endoscopy and Other Interventional Techniques, vol. 21, no. 8, pp. 13441348, 2007.

[8] R. N. Sammour, L. Saiegh, I. Matter et al., "Adrenalectomy for adrenocortical adenoma causing Cushing's syndrome in pregnancy: a case report and review of literature," European Journal of Obstetrics Gynecology and Reproductive Biology, vol. 165, no. 1, pp. 1-7, 2012.

[9] C. F. Close, M. C. Mann, J. F. Watts, and K. G. Taylor, "ACTHindependent Cushing's syndrome in pregnancy with spontaneous resolution after delivery: control of the hypercortisolism with metyrapone," Clinical Endocrinology, vol. 39, no. 3, pp. 375379,1993

[10] J. M. C. Connell, J. Cordiner, D. L. Davies, R. Fraser, B. M. Frier, and S. G. McPherson, "Pregnancy complicated by Cushing's syndrome: potential hazard of metyrapone therapy. Case report," British Journal of Obstetrics and Gynaecology, vol. 92, no. 11, pp. 1192-1195, 1985.

[11] V. Hána, M. Dokoupilová, J. Marek, and R. Plavka, "Recurrent ACTH-independent Cushing's syndrome in multiple pregnancies and its treatment with metyrapone," Clinical Endocrinology, vol. 54, no. 2, pp. 277-281, 2001.

[12] C. Wallace, E. L. Toth, R. Z. Lewanczuk, and K. Siminoski, "Pregnancy-induced Cushing's syndrome in multiple pregnancies," The Journal of Clinical Endocrinology \& Metabolism, vol. 81, no. 1, pp. 15-21, 1996.

[13] V. Garla, R. Kheetan, and T. Saleem, "Cushing's syndrome in pregnancy: a diagnostic conundrum," The West Virginia Medical Journal, vol. 109, no. 6, pp. 34-36, 2013.

[14] J. Newell-Price, P. Trainer, M. Besser, and A. Grossman, "The diagnosis and differential diagnosis of Cushing's syndrome and pseudo-Cushing's states," Endocrine Reviews, vol. 19, no. 5, pp. 647-672, 1998

[15] G. Arnaldi, A. Angeli, A. B. Atkinson et al., "Diagnosis and complications of Cushing's syndrome: a consensus statement," Journal of Clinical Endocrinology and Metabolism, vol. 88, no. 12, pp. 5593-5602, 2003.

[16] J. R. Lindsay, J. Jonklaas, E. H. Oldfield, and L. K. Nieman, "Cushing's syndrome during pregnancy: personal experience and review of the literature," The Journal of Clinical Endocrinology and Metabolism, vol. 90, no. 5, pp. 3077-3083, 2005.

[17] J. Newell-Price, X. Bertagna, A. B. Grossman, and L. K. Nieman, "Cushing's syndrome," The Lancet, vol. 367, no. 9522, pp. 16051617, 2006.

[18] L. Cousins, L. Rigg, D. Hollingsworth et al., "Qualitative and quantitative assessment of the circadian rhythm of cortisol in pregnancy," The American Journal of Obstetrics and Gynecology, vol. 145, no. 4, pp. 411-416, 1983.

[19] J. Lindholm and N. Schultz-Möller, "Plasma and urinary cortisol in pregnancy and during estrogen-gestagen treatment," Scandinavian Journal of Clinical \& Laboratory Investigation, vol. 31, no. 1, pp. 119-122, 1973.

[20] E. M. Scott, H. H. G. McGarrigle, and G. C. L. Lachelin, "The increase in plasma and saliva cortisol levels in pregnancy is not 
due to the increase in corticosteroid-binding globulin levels," Journal of Clinical Endocrinology and Metabolism, vol. 71, no. 3, pp. 639-644, 1990.

[21] B. R. Carr, C. R. Parker Jr., J. D. Madden, P. C. MacDonald, and J. C. Porter, "Maternal plasma adrenocorticotropin and cortisol relationships throughout human pregnancy," The American Journal of Obstetrics and Gynecology, vol. 139, no. 4, pp. 416-422, 1981.

[22] J. S. Bevan, M. H. Gough, M. D. G. Gillmer, and C. W. Burke, "Cushing's syndrome in pregnancy: the timing of definitive treatment," Clinical Endocrinology, vol. 27, no. 2, pp. 225-233, 1987.

[23] C. Blanco, E. Maqueda, J. A. Rubio, and A. Rodriguez, "Cushing's syndrome during pregnancy secondary to adrenal adenoma: metyrapone treatment and laparoscopic adrenalectomy," Journal of Endocrinological Investigation, vol. 29, no. 2, pp. 164$167,2006$.

[24] A. B. Eisenstein, R. Karsh, and I. Gall, "Occurrence of pregnancy in Cushing's syndrome," The Journal of clinical endocrinology and metabolism, vol. 23, pp. 971-974, 1963.

[25] M. Aishima, M. Tanaka, M. Haraoka, and S. Naito, "Retroperitoneal laparoscopic adrenalectomy in a pregnant woman with Cushing's syndrome," Journal of Urology, vol. 164, no. 3, pp. 770771, 2000.

[26] V. E. Pricolo, J. M. Monchik, R. A. Prinz, S. DeJong, D. A. Chadwick, and R. P. Lamberton, "Management of Cushing's syndrome secondary to adrenal adenoma during pregnancy," Surgery, vol. 108, no. 6, pp. 1072-1078, 1990.

[27] J. K. Jacobs, R. E. Goldstein, and R. J. Geer, "Laparoscopic adrenalectomy: a new standard of care," Annals of Surgery, vol. 225, no. 5, pp. 495-502, 1997.

[28] T. Z. Nursal, K. Caliskan, E. Ertorer, A. Parlakgumus, and G. Moray, "Laparoscopic treatment of primary hyperaldosteronism in a pregnant patient," Canadian Journal of Surgery, vol. 52, no. 5, pp. E188-E190, 2009.

[29] S. Toutounchi, A. Makowska, E. Krajewska et al., "Laparoscopic treatment of Cushing's syndrome in a woman in late pregnancy: a case presentation," Wideochirurgia I Inne Techniki Maloinwazyjne, vol. 6, no. 4, pp. 261-263, 2011. 


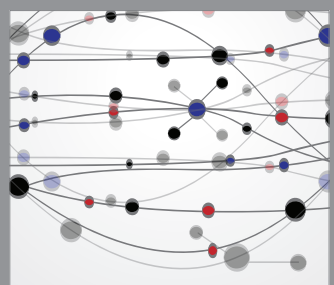

The Scientific World Journal
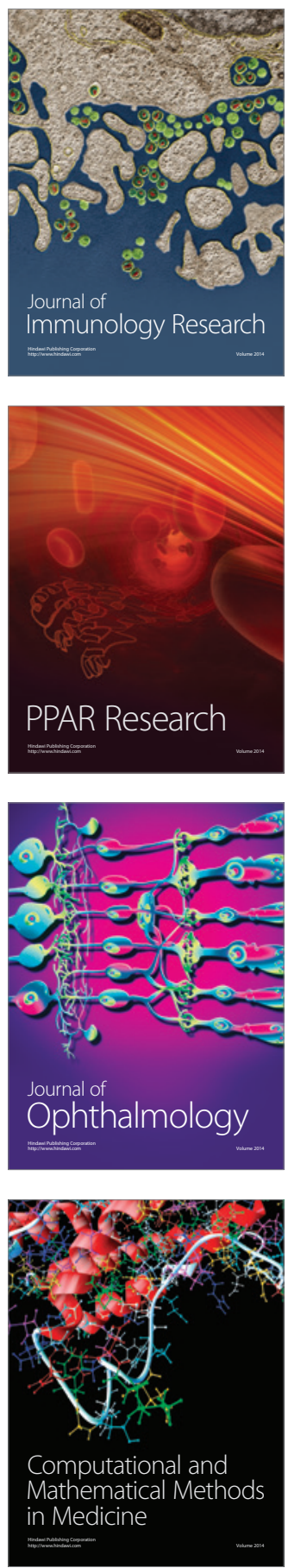

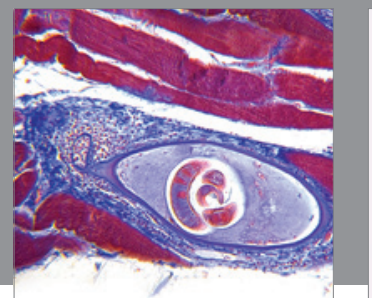

Gastroenterology

Research and Practice
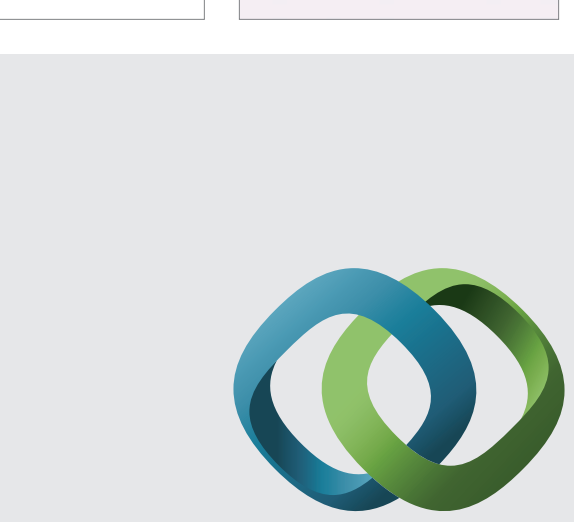

\section{Hindawi}

Submit your manuscripts at

http://www.hindawi.com
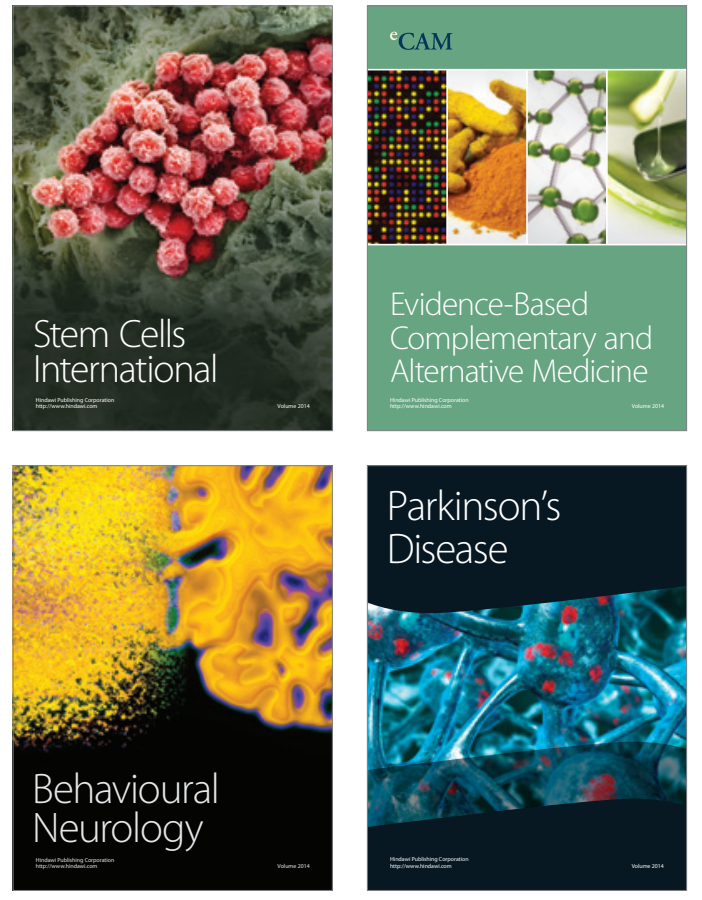
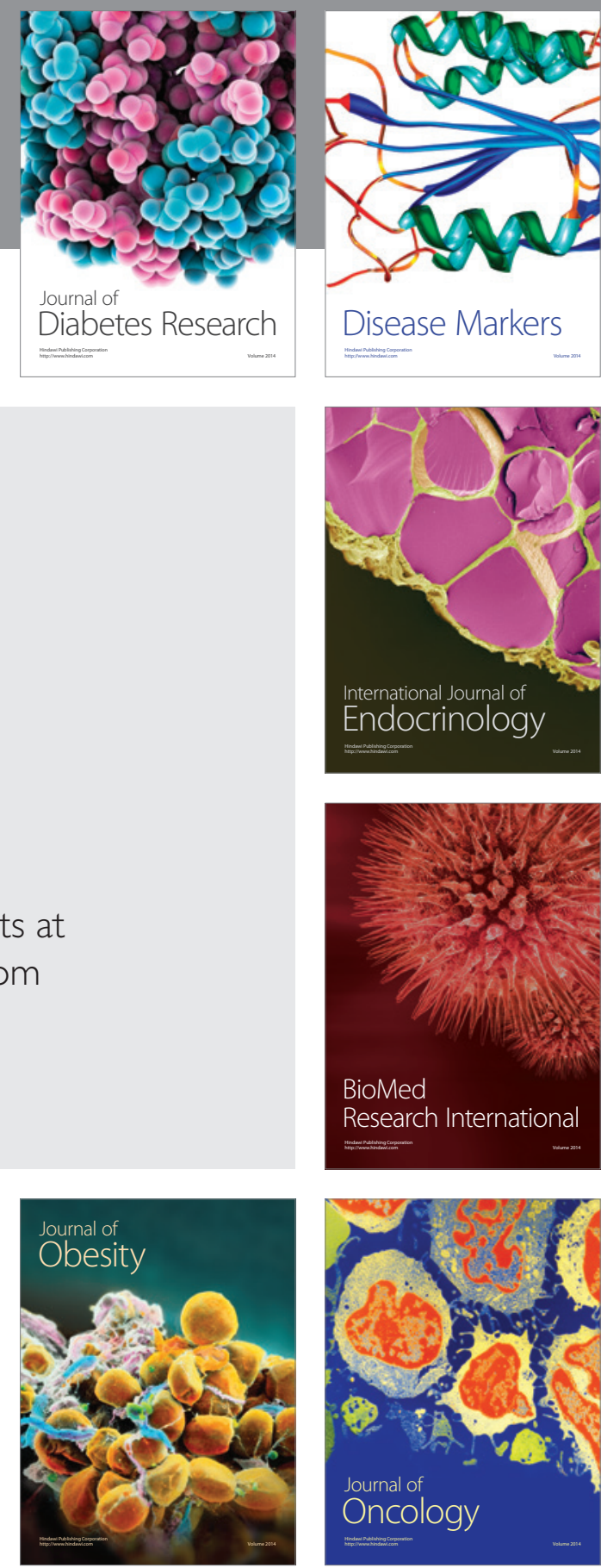

Disease Markers
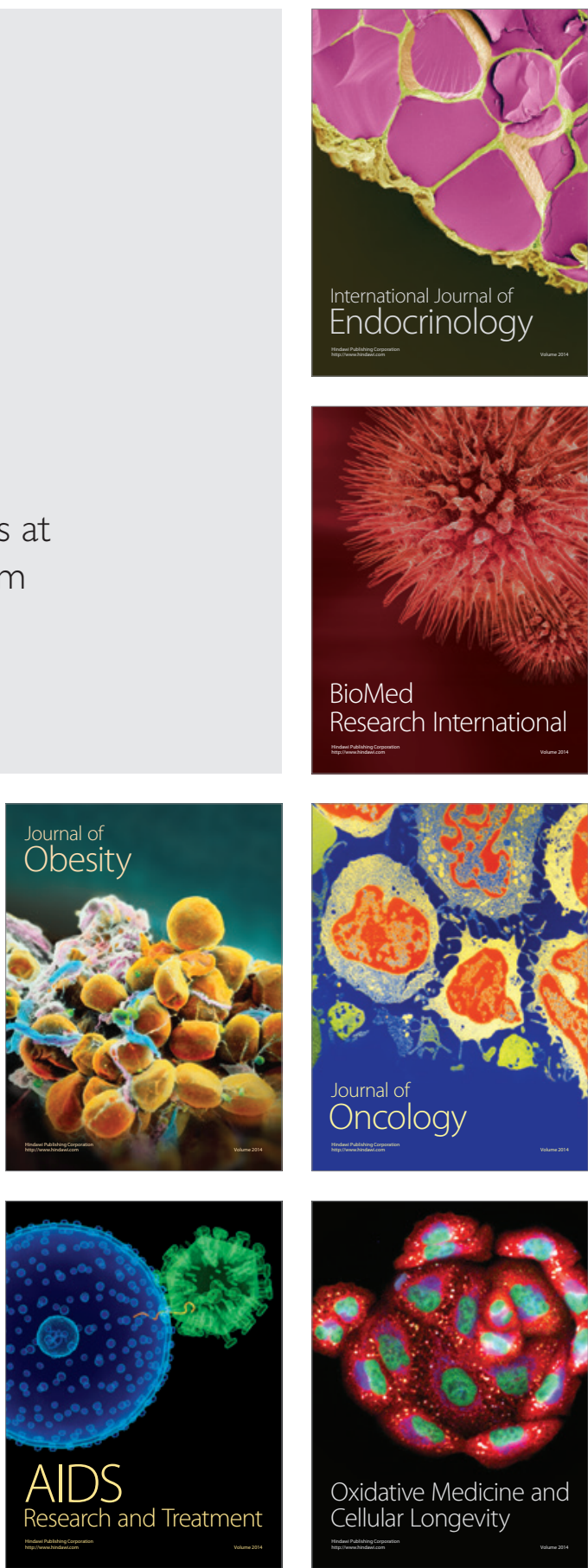